\title{
Introduction
}

\section{The First Congress of the International Academy of Digital Pathology: Digital pathology comes of age}

\author{
Yukako Yagi*, Marcial Garcia Rojo, Klaus Kayser, Gian Kayser, Arvydas Laurinavicius, \\ Vincenzo Della Mea, Bruce Levy, Jacques Klossa, Gary Tearney, Janus Szymas, \\ Yasunari Tsuchihashi and Bernard Têtu
}

International Academy of Digital Pathology, Boston, MA, USA

The First Congress of the International Academy of Digital Pathology (IADP) was held August 3-5, 2011 in Quebec City, Province Quebec, Canada. The IADP aroses as an evolution of the International Academy of Telepathology (IAT). The IADP is a non-profit organization whose mission is to advance information technology in the practice of pathology. The IADP aims to promote the standardization of digital pathology; promote research, innovation, development and good practice of information and communication technologies in pathology; exchange information between research scientists and pathologists through establishment of digital pathology networks; and provide education, research and development to enable the effective implementation of digital pathology in developing countries.

The Congress held in Quebec City met the mission and aims of the IADP. It had presenters and attendees from eighteen (18) countries, with a broad range of professionals; including pathologists, researchers and engineers. There were a total of sixty-two (62) presentations at the Congress, including forty-nine (49)

${ }^{*}$ Corresponding author. E-mail: yyagi@ partners.org. platform presentations and thirteen (13) poster presentations over the three days of the Congress.

Standardization in digital pathology is necessary for the maturation of this field. Standardization will facilitate the use of digital pathology in daily practice, allow the development of digital pathology networks, and enhance the effective exchange of digital information. Not surprisingly, this area was well represented at the Congress with presentations from three continents. The perspective and current work of groups that create standards, such as DICOM, EURO-TELEPATH and the CAP were presented. Numerous talks involved the latest research on techniques to establish standards for image quality, image color, and the use of digital pathology to assist in standardization of pathology diagnoses.

The creation of digital pathology networks and work towards the implementation of digital pathology in developing countries was another major focus of the Congress. Presentations were delivered on the experiences of currently functioning telepathology networks and the use of telepathology to provide diagnoses and consultation in pathology. One highlight of the Congress was the demonstration of a telepathology system being used at Laval University in Quebec. One 
session of the Congress focused on digital pathology in the developing counties and beyond.

Research and development in digital pathology is necessary for the future of this field. There were many excellent talks and posters on the latest work being conducted. Areas presented at this Congress included image analysis, pattern and specific feature recognition, the use of digital pathology to assist in diagnosis, techniques in the efficient and accurate display of digital pathology images, working in the third dimension of pathology, and collaborative research between digital pathology and radiology. Also presented were numerous examples and pilot studies of the utilization of digital pathology in education and training.

Also included in the Congress was a company discussion forum. Several manufacturers of digital pathology equipment and software discussed their visions of the future of digital pathology and encouraged greater communication and collaboration between academia, clinical practice and industry. Industry's support of the IADP was critical to the success of this first Congress.

In conclusion, the First Congress of the IADP was a great success. It displayed the commitment of the IADP towards its mission and aims. The breath and strength of the scientific presentations demonstrated the advancement and latest research in our field. The future of digital pathology is clearly here and its long anticipated promises are being realized. 


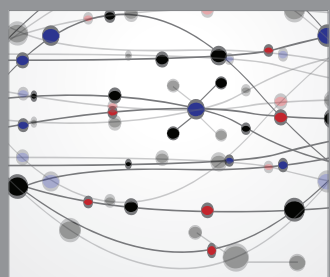

The Scientific World Journal
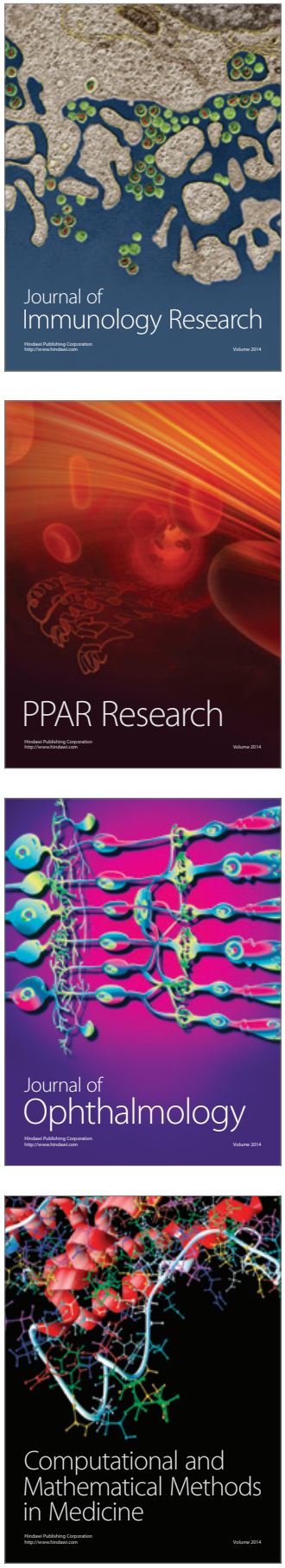

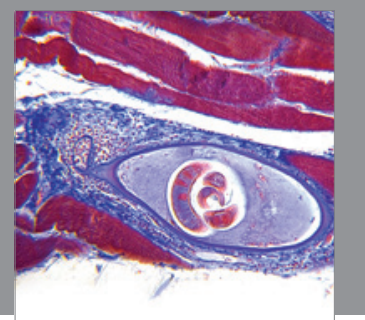

Gastroenterology

Research and Practice
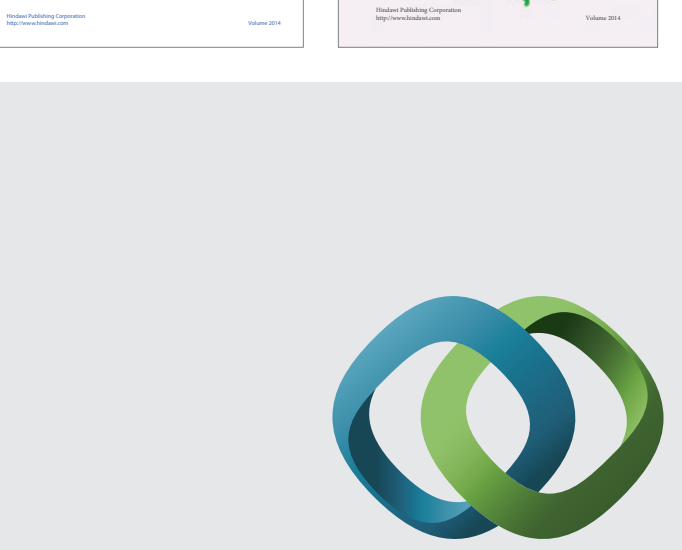

\section{Hindawi}

Submit your manuscripts at

http://www.hindawi.com
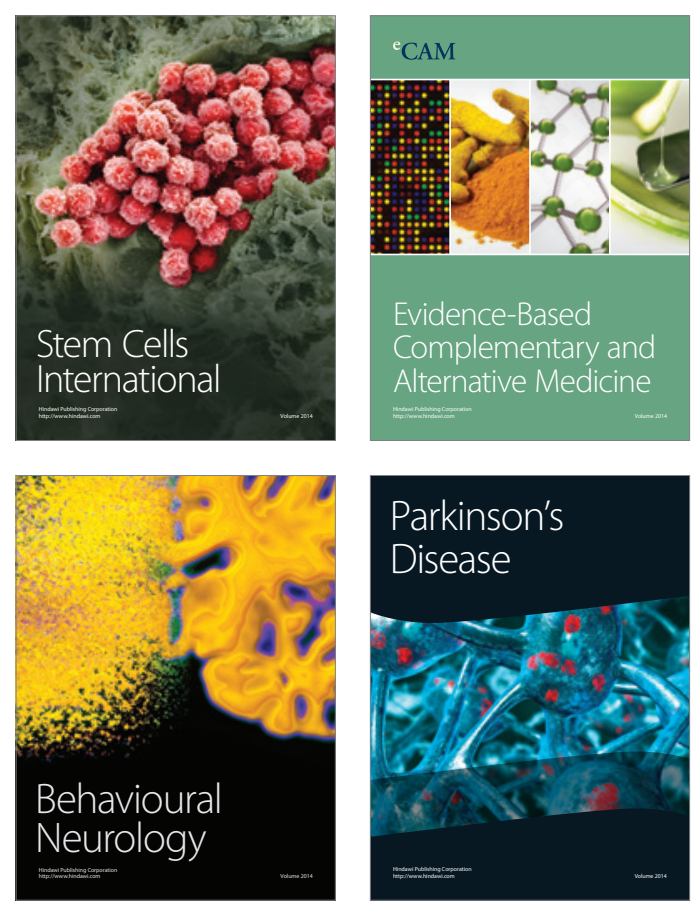

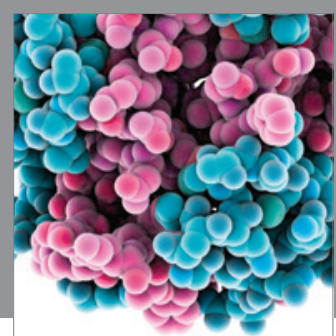

Journal of
Diabetes Research

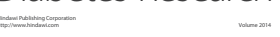

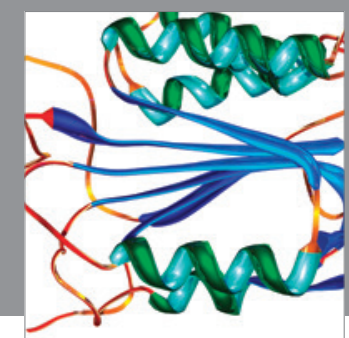

Disease Markers
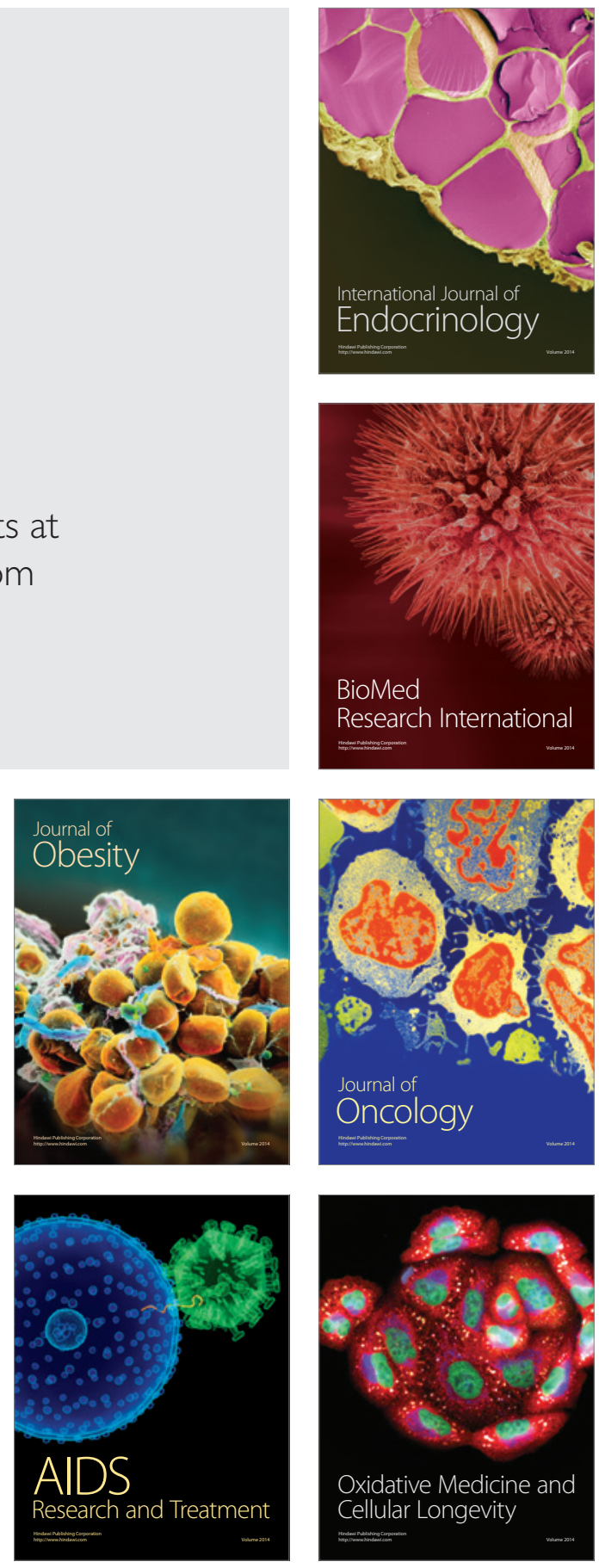